\title{
BMJ Open Activation of professional and personal network relations when experiencing a symptom: a population-based cross- sectional study
}

\author{
Sandra Elnegaard, ${ }^{1}$ Rikke Sand Andersen, ${ }^{2,3}$ Anette Fischer Pedersen, ${ }^{2}$ \\ Dorte Ejg Jarbøl ${ }^{1}$
}

To cite: Elnegaard S, Andersen RS, Pedersen AF, et al. Activation of professional and personal network relations when experiencing a symptom: a population-based crosssectional study. BMJ Open 2017;7:e017620. doi:10.1136/ bmjopen-2017-017620

- Prepublication history for this paper is available online. To view these files, please visit the journal online (http://dx.doi org/10.1136/bmjopen-2017017620).

Received 5 May 2017

Revised 9 August 2017

Accepted 7 September 2017

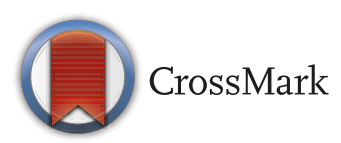

${ }^{1}$ Research Unit of General Practice, Department of Public Health, University of Southern Denmark, 5000 Odense C, Denmark

${ }^{2}$ Research Unit for General Practice, Department of Public Health, Danish Research Centre for Cancer Diagnosis in Primary Care-CaP, Aarhus University, Bartholins Allé 2, 8000 Aarhus C, Denmark

${ }^{3}$ Department of Anthropology, School of Culture and Society, Aarhus University, Moesgaard Alle, 8270 Højbjerg, Denmark

Correspondence to

Dr Sandra Elnegaard;

selnegaard@health.sdu.dk

\section{ABSTRACT}

Objective To describe patterns of disclosure of symptoms experienced among people in the general population to persons in their personal and/or professional network.

Design A population-based cross-sectional study. Data were collected from a web-based survey.

Setting The general population in Denmark.

Participants 100000 individuals randomly selected, representative of the adult Danish population aged $\geq 20$ years were invited. Approximately $5 \%$ were not eligible for inclusion. 49706 (men=23240; women=26466) of 95253 eligible individuals completed the questionnaire; yielding a response rate of $52.2 \%$. Individuals completing all questions regarding social network relations form the study base $(n=44313)$.

Primary and secondary outcome measures Activation of personal and/or professional relations when experiencing a symptom.

Results The 44313 individuals reported in total 260079 symptom experiences within the last 4 weeks. No professional network relation was used in two-thirds of all reported symptoms. The general practitioner (GP) was the most frequently reported professional relation activated (22.5\%). People reporting to have available personal relations were slightly less inclined to contact the GP $(21.9 \%)$ when experiencing a symptom compared with people with no reported personal relations (26.8\%). The most commonly activated personal relations were spouse/partner (56.4\%) and friend (19.6\%). More than a quarter of all reported symptom experiences was not shared with anyone, personal nor professional. The symptom experiences with the lowest frequency of network activation were symptoms such as black stool, constipation, change in stool texture and frequent urination.

Conclusion This study emphasises variation in the activation of network relations when experiencing a symptom. Symptoms were shared with both personal and professional relations, but different patterns of disclosures were discovered. For symptoms derived from the urogenital or colorectal region, the use of both personal and professional relations was relatively small, which might indicate reticence to involve other people when experiencing symptoms of that nature.
Strengths and limitations of this study

- This study was based on data from a large crosssectional nationwide population-based study, inviting 100000 randomly selected Danish individuals in the age group 20 to 107 years.

- Data were based on individuals who had reported actual experiences of symptoms, thus reflecting true actions rather than hypothetical considerations.

- Telephone interviews offered to participants without opportunity to complete the online survey enabled additional responses from individuals aged 80 years or above, who are usually rarely represented in surveys.

- Based on data extracted from the questionnaire, it was not possible to obtain information on the quality or content of the dialogues between the respondents and their relations. We can solely describe whether a relation was activated or not.

\section{INTRODUCTION}

The epidemiology of symptom experiences, and what is often referred to as the symptom iceberg, referring to the observation that only a minor proportion of all experienced symptoms are shared with a general practitioner (GP), had its breeding ground in the study by Last in the $1960 \mathrm{~s} .{ }^{1}$ Last illustrated that diseases presented to GPs only represent the tip of the iceberg and thus hypothesised that the majority of symptom experiences are managed in a private setting. ${ }^{2}$ Contemporary studies also suggest that the majority of symptoms experienced in the general population are not presented to the GP or other healthcare providers and remain below the so-called 'water line'. ${ }^{3-5}$ Elliot et al for example describes that only $12 \%$ of symptoms led to a consultation with a primary health professional. ${ }^{3}$

Symptom iceberg studies are of relevance because they provide insights into the prevalence of symptom experiences and the 
social organisation of symptom management. Traditional symptom iceberg studies, however, primarily explored changes of 'the water line' and asked the binary question: did you seek healthcare or not. We thus have only sparse information on the variety of social encounters individuals engage in when experiencing symptoms and whether it is possible to identify social patterns of network activation that are relevant to understanding how or when people contact the GP. This is of relevance as some research suggests that disclosure of symptoms might affect the timing of the healthcare seeking. A review of factors associated with healthcare seeking for symptoms indicative of serious diseases, such as cancer, has identified a number of triggers; demographic factors (eg, age, gender), psychological factors (eg, concern, fear), behavioural factors (eg, self-medication, watchful waiting) and social relations (eg, influence of family and friends) ${ }^{67}$ In particular, disclosure of a symptom to a family member or friend has been identified as a trigger in favour of seeking medical help for potentially alarming symptoms. ${ }^{89}$

Recounting of symptoms to a family member or friend can, however, either prompt or demotivate individuals in the decision to seek medical help, especially within socioeconomic groups and categories of symptoms. ${ }^{5}$

In adding to this binary-focused research on symptom experiences and healthcare seeking, sociologist Pescosolido and colleagues conducted studies exploring patterns of social network activation in relation to illness episodes. ${ }^{10}$ In this approach, contacting the GP with a symptom experienced is not an 'either/or' but potentially part of a larger social pattern. Overall, they showed that there appears to be a limited repertoire of patterns which are affected by the social setting and medical incidents, which in turn influence the network opportunities. Inspired by Pescosolido and colleagues' work on social network activation, ${ }^{10}$ the objective of this study is to describe patterns of disclosure of symptoms experienced among people in the general population to persons in the personal and/or professional network in the context of the Danish welfare state.

\section{METHOD}

\section{Study design}

This Danish nationwide cross-sectional study comprising a random sample of 100000 people, representative of the adult Danish population aged 20 years or above, uses data from the Danish Symptom Cohort, which has been described previously. ${ }^{11}{ }^{12}$ Baseline data presented in this paper were collected in a web-based survey. The data collection was conducted from June to December 2012.

\section{Subjects and sampling}

All Danish citizens are registered with a unique personal identification number in the Danish Civil Registration System (CRS), which contains information on any Danish resident's date of birth, gender, migration and so on. ${ }^{13}$
The sample for this study was randomly selected using the CRS and was invited to participate in the survey. Each individual received a postal letter explaining the purpose of the study. In the letter, a unique 12-digit login to a secure web page was included. This provided access to a comprehensive web-based questionnaire. To prevent the exclusion of people with no access to a computer, a tablet or a smartphone, the participants were offered the opportunity to respond to the survey in a telephone interview. ${ }^{11}$

\section{Questionnaire}

The overall concept of the questionnaire was to measure the prevalence of self-reported symptom experiences in the general population and explore dimensions related to activation of social networks and healthcare-seeking decisions.

To explore the prevalence of different symptom experiences, 44 different predefined symptom categories were included based on a review of literature and national and international cancer referral guidelines (4-6). In addition, unspecific general symptoms which often are presented to the GP, for example, back pain, headache and tiredness, were included.

The questionnaire was pilot and field tested and adjusted accordingly. The methodological framework for developing the questionnaire is described in details elsewhere. $^{11}$

Items regarding each of the included symptom categories were phrased: 'Have you experienced any of the following bodily sensations, symptoms or discomforts within the past 4 weeks?' For each symptom experience reported, respondents were asked whom they talked to, if anyone concerning the symptom. Two dimensions of social network relations were explored, a professional and a personal dimension, respectively. The first item concerning the professional dimension was phrased: 'Have you contacted your general practitioner with the symptom or discomfort, in person, by phone or by e-mail?' Afterwards respondents were asked: 'Which of the following other healthcare professionals or therapists have you talked to regarding the symptoms or discomforts (through appointment, by telephone or by email)? The following healthcare professionals were selectable: Another doctor (practising specialist, out-of-hours physician or hospital physician), physiotherapist/chiropractor, home help/district nurse, pharmacy staff, alternative therapist (eg, homeopath, healer, reflexologist), none and another category. The items concerning the personal relations were phrased: 'Which of the following members of your family or social network have you talked to about the symptoms or discomforts? The personal relations selectable were spouse/partner, children, parents, colleague/classmate, friend, neighbour, siblings, none and another category. More than one of the relations could be ticked off.

To qualify the identification of the personal and professional relations activated when experiencing a symptom, we found it relevant to estimate aspects of social network 
relations, that is, whether the respondents had available personal relations or accessibility to other people. For this purpose, the following four items were constructed: (1) 'How often are you in contact with friends, acquaintances or family that you do not live with? Contact indicates that you are together, talking with each other on the phone, writing to each other etc.' (daily or almost daily/once or twice a week/once or several times a month/less than once a month/Never/I don't know). (2) 'If you become ill and need help with practical things, can you count on help from others? (Others means people you do not live with)' (Yes, Definitely/Yes, Maybe/No). (3) 'Does it ever happen that you are alone, even if you want to be in the company of others?' (Yes, Often/Yes, Once in a while/ Yes, But rarely/No, Never or Almost never). (4) 'Do you have someone to talk to if you have problems or need support?' (Yes, Often/Yes, Mostly/Yes, Sometimes/No, Never or Almost never).

On the basis of these four items, individuals were categorised as having an 'available relation' if the following responses were chosen: Often in contact with others (daily or almost daily/once or twice a week/once or several times a month), having available persons who can help (yes, definitely/yes, maybe), being alone when desiring to be with others (never or almost never/rarely/once in a while) and having a person to talk to in case of problems (often/mostly/sometimes).

\section{Data analysis}

The data set used in the analyses was constructed by merging all reported symptoms experienced by the respondents with each individual symptom experience used as study case.

Basic descriptive analyses were used to study the activation of each personal and professional relation when experiencing a symptom. Activation is somewhat agent neutral in the sense that the data do not allow for insight into who approached who. This is of particular relevance in respect to the personal relations.

To explore common patterns of relations used when experiencing a symptom, cluster analysis was performed. These analyses were repeated for the subgroup of people who were categorised as having available personal relations or accessibility to other people.

Prevalences of various combinations of two relations activated when experiencing a symptom were calculated and displayed in an expanded two times two table. Proportions were calculated as percentages $(\%)$, based on the binominal distribution. For each relation, the diagonal across the matrix sums up to $100 \%$.

To estimate the proportion of the 44 different symptom experiences with regard to the possible network relations, three categories of relations were defined; professional relations, personal relations and neither use of personal nor professional, respectively. Proportions were calculated as percentages (\%), based on the binominal distribution.

All data analyses were conducted using STATA statistical software V.14.1 (StataCorp).
RESULTS

Of the 100000 randomly selected individuals, 4474 (4.7\%) were not eligible for inclusion. Of the $95253(95.3 \%)$ eligible subjects, 49706 individuals completed the questionnaire, yielding a response rate of 52.2\%. Some 1208 $(2.4 \%)$ completed the questionnaire by telephone interview (figure 1 ). The respondents were fairly representative of the study sample and thus representative of the Danish population according to ethnicity, socioeconomic and demographic variables. However, slightly more respondents were females, married/living together, had a high educational and income level and were attached to the labour market. ${ }^{12}$

\section{Personal and professional relations activated when experiencing a symptom}

A total of 44313 individuals answered all the relevant items with regard to activation of social network relations and form the basis for this study, figure 1 . They reported a total of 260079 symptoms (table 1 ).

For $78214(30.1 \%)$ of all symptom experiences, no personal relation was activated. The most commonly activated personal relation was spouse/partner, who was activated in $56.4 \%$ of the symptom experiences, followed by friends $(19.6 \%)$. No professional network relation was activated in 172148 (66.2\%) of the symptom experiences. The most frequently reported professional relation was the GP, who was contacted for $22.5 \%$ of the symptom experiences (table 1).

\section{Patterns of network activation}

When merging all relations into one source of network including both professional and personal relations, nearly 3000 different patterns of relations occurred for the 260079 symptoms reported. The 20 most commonly activated patterns of relations are listed in table 2. The most prevalent pattern was the activation of no relations. More than a quarter $(26.1 \%)$ of all reported symptom experiences was not shared with anyone; neither personal nor professional. Disclosure of symptoms to one's spouse/partner was almost consistently throughout the first 10 patterns, standing alone or in combination with either a professional relation or another personal relation. Involving both personal and professional relations by activating a spouse/partnerand the GP was the third most common pattern of network relations (table 2).

Even though 2975 patterns occurred, two-thirds of all symptom experiences were represented in the first 10 patterns of relations. This contributes to a limited repertoire of patterns of relations, most of them pluralistic and some single (table 2).

For the subgroup of respondents who reported an available network of relations, small differences were seen in the patterns of relations compared with those of the full sample. A tendency towards higher activation of personal relations and less activation of both the GP and other doctors was seen in this group. Furthermore, this group was less inclined to contact the GP (21.9\%) when 
Sampling frame: 100,000 randomly selected Danish people aged $\geq 20$ years

men $=48,910(48.9 \%) ;$ women $=51,090(51.1 \%)$

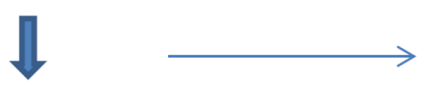

Eligible for the study: $95,253(95.3 \%)$

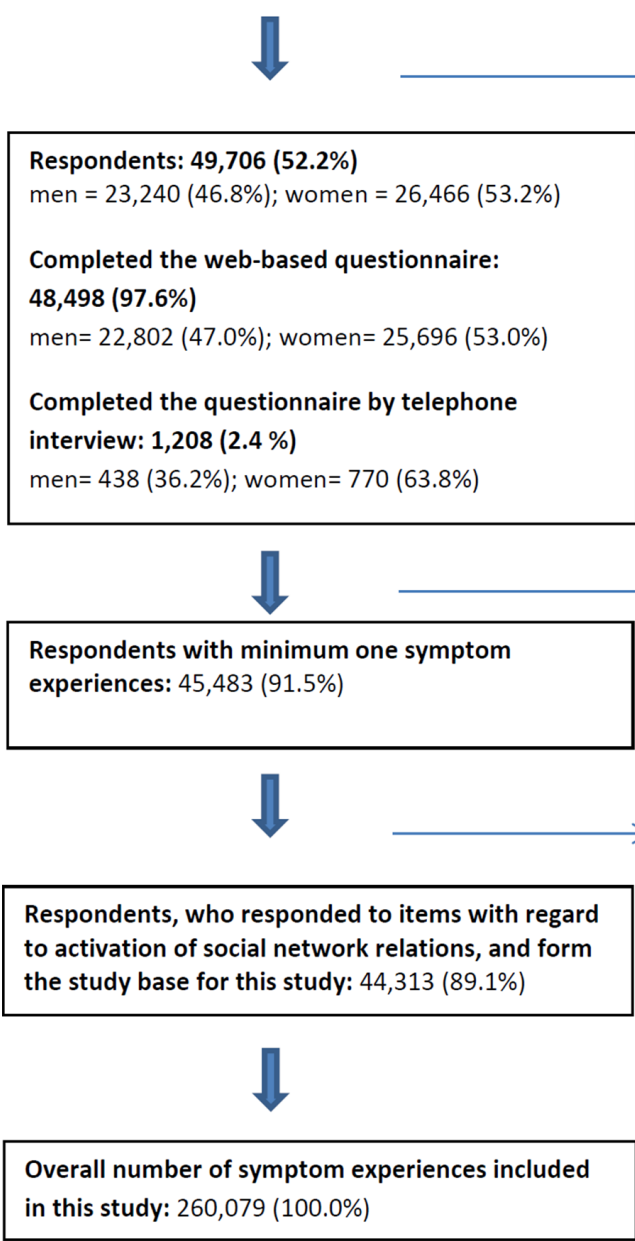

Figure 1 Study sample.

experiencing a symptom compared with people without an available network of relations or accessibility to other people $(26.8 \%)$ (table 2$)$.

\section{Density of patterns}

The figures highlighted in bold in table 3 represent patterns with high densities across each cluster of two relations using an arbitrary cut-off at $50 \%$ level. ${ }^{10}$ For each relation, the diagonal across the matrix sums up to $100 \%$. The main collaborator in the patterns comprising the GP was the spouse/partner $(70.9 \%)$. This means that when the GP is contacted with regard to a symptom experience, the spouse/partner is involved in $70.9 \%$ of the cases. Conversely, when the spouse/partner was activated with regard to a symptom experience, the GP was only involved in less than one-third of the cases (28.3\%).

\section{Excluded: $4,747(4.7 \%)$}

Dead: 315

Addresses unknown: 961

Suffering from severe illness: 1,972

Language problems: 885

Moved abroad: 614

\section{Non-respondents: $\mathbf{4 5 , 5 4 7}(\mathbf{4 7 . 8 \% )}$}

men $=23,407(51.4 \%)$, women $=22,140(48.6 \%)$

Not wishing to participate (indicated by

telephone/email or postal contact): 25,690

Indicated 'other reasons' for non-participation: 318

No contact achieved in the reminder procedure: 19,539

Respondents without any symptom experiences: $4,223(8.5 \%)$

Respondents without answers to all items relevant to this study: $1,170(2.4 \%)$

Across all possible relations listed in table 3, the spouse/ partner was one of the main relations to be activated when experiencing a symptom. When a more distant personal relation such as a neighbour or colleague was activated, it was often in combination with various different relations. This is opposite to the patterns including a spouse/ partner, who was often activated as a single relation or in combination with limited close relations. When a professional relation was activated, it was often in combination with a GP. Looking at the patterns comprising none personal relation the most activated relation was the GP $(8.1 \%)$ (table 3$)$.

\section{Type of symptom and network activation}

The symptoms with the highest proportion of activation of neither personal nor professional relations were 
Table 1 Descriptive overview of study sample with regard to symptom experiences and reported relations

\begin{tabular}{|c|c|c|c|c|}
\hline & \multicolumn{2}{|c|}{ Study sample } & \multicolumn{2}{|c|}{$\begin{array}{l}\text { Number of } \\
\text { symptoms }\end{array}$} \\
\hline & $\mathbf{N}$ & $(\%)$ & $\mathbf{n}$ & (\%) \\
\hline \multicolumn{5}{|c|}{ Study sample } \\
\hline Overall & 44313 & (100.0) & 260079 & (100.0) \\
\hline \multicolumn{5}{|l|}{ Gender } \\
\hline Men & 20546 & (46.4) & 107192 & (41.2) \\
\hline Women & 23767 & (53.6) & 152887 & (58.7) \\
\hline \multicolumn{5}{|l|}{ Age } \\
\hline 20-39 & 11262 & (25.4) & 77870 & (29.9) \\
\hline $40-59$ & 18224 & $(41.1)$ & 106195 & $(40.8)$ \\
\hline $60-79$ & 13641 & $(30.8)$ & 68806 & (26.5) \\
\hline $80+$ & 1186 & (2.7) & 7208 & (2.8) \\
\hline \multicolumn{5}{|c|}{ Personal relation } \\
\hline \multicolumn{3}{|c|}{ Spouse/partner } & 146745 & (56.4) \\
\hline \multicolumn{3}{|l|}{ Children } & 31177 & $(12.0)$ \\
\hline \multicolumn{3}{|l|}{ Parents } & 29290 & (11.3) \\
\hline \multicolumn{3}{|c|}{ Colleague/classmate } & 28335 & (10.9) \\
\hline \multicolumn{3}{|l|}{ Friend } & 51065 & (19.6) \\
\hline \multicolumn{3}{|c|}{ Neighbour } & 6537 & (2.5) \\
\hline \multicolumn{3}{|l|}{ Sibling } & 3279 & (1.3) \\
\hline \multicolumn{3}{|l|}{ None } & 78214 & $(30.1)$ \\
\hline \multicolumn{3}{|l|}{ Other } & 2692 & (1.0) \\
\hline \multicolumn{5}{|c|}{ Professional relation } \\
\hline \multicolumn{3}{|c|}{ General practitioner } & 58504 & (22.5) \\
\hline \multicolumn{3}{|c|}{ Another doctor } & 41539 & $(16.0)$ \\
\hline \multicolumn{3}{|c|}{ Physiotherapist/chiropractor } & 12456 & $(4.8)$ \\
\hline \multicolumn{3}{|c|}{ Home help/district nurse } & 2611 & (1.0) \\
\hline \multicolumn{3}{|c|}{ Pharmacy staff } & 3754 & (1.4) \\
\hline \multicolumn{3}{|c|}{ Alternative therapist } & 9455 & (3.6) \\
\hline \multicolumn{3}{|l|}{ None } & 172148 & $(66.2)$ \\
\hline \multicolumn{3}{|l|}{ Other } & 6927 & (2.7) \\
\hline
\end{tabular}

symptoms such as black stool, constipation and change in stool texture. The proportion of activating a professional relation was highest for blood in urine, shortness of breath and back pain. Personal relations were most often used when experiencing back pain, repeated vomiting, feeling unwell and tiredness. Back pain was the symptom which overall activated most relations, as only $8.8 \%$ of all experienced back pains were kept to oneself (table 4).

\section{DISCUSSION}

\section{Article summary}

Symptoms are shared with both the personal and the professional network, but different patterns of disclosures were discovered. More than a quarter of all reported symptom experiences were not shared with anyone; personal nor professional. Whether individuals had an available network or not, the GP was the most frequently reported professional relation activated, although people reporting available network relations were slightly less inclined to contact their GP. Across all possible relations, the spouse/partner was the main relation to be activated when experiencing a symptom and involved in the majority of symptoms also shared with the GP.

The study also emphasises variation in disclosure of different symptoms. For symptoms derived from the urogenital or colorectal region, the use of both personal and professional relations was relatively small, which might indicate reticence to involve other people when experiencing symptoms that might be subject to stigmatisation, embarrassment or shame.

\section{Strengths and limitations of this study}

This study was a large cross-sectional nationwide population-based study, inviting 100000 people randomly selected from the Danish CRS register, representative of the adult Danish population aged 20 years or above. To our knowledge, such a large-scale nationwide population-based study, investigating a wide range of self-reported symptom experiences and dimensions related to network activation, has not previously been conducted.

The response rate of $52.2 \%$ was comparable or even higher as compared with previous surveys measuring symptom prevalence in the general population. ${ }^{314}$ Although a preponderance of the respondents were women, and the respondents were slightly older than the non-respondents, the respondents were fairly representative of the general Danish population. However, differences between the respondents and the non-respondents regarding other parameters, which might include a risk of overestimating or underestimating the proportion of GP contacts, cannot be eliminated. For more details, see Elnegaard et al. ${ }^{12}$

To avoid a possible selection bias due to the web-based design of the questionnaire, participants without access to a computer, a smartphone or a tablet were offered the possibility of conducting the survey as a telephone interview. These interviews enabled additional responses from the oldest individuals, aged 80 years or above, who usually are rarely represented in surveys.

The participants were asked to recall symptom experiences within the preceding 4 weeks and whether they had contacted a personal or professional relation with these symptoms at any time. Recall bias cannot be completely eliminated in questionnaire studies. ${ }^{15}$ Some may misplace older symptom experiences in the specified timeframe due to the severity of symptoms or because they had contacted a GP about them. ${ }^{16}$ Others may have forgotten about a symptom experience or a GP contact, because the symptom turned out to be nothing to worry about or simply due to memory decay. ${ }^{17}$ The recall period of 4 weeks was chosen to ensure enough symptom experiences to obtain statistically precise estimates, even for rare symptoms, while still assuming that individuals could 
Table 2 The most frequent patterns of relations reported with regard to a symptom experience

\begin{tabular}{|c|c|c|c|c|}
\hline \multirow[b]{2}{*}{ Patterns of relations } & \multicolumn{2}{|c|}{$\begin{array}{l}\text { Full sample } \\
(\mathrm{n}=260079)\end{array}$} & \multicolumn{2}{|c|}{$\begin{array}{c}\text { Subgroup with available relations } \\
(n=226013)\end{array}$} \\
\hline & n (\%) & Rank & $\mathrm{n}(\%)$ & Rankt \\
\hline None & $67774(26.1)$ & 1 & $57625(25.4)$ & 1 \\
\hline Spouse/partner & $61050(23.5)$ & 2 & $55307(24.4)$ & 2 \\
\hline Spouse/partner+GP & $8773(3.4)$ & 3 & $7763(3.4)$ & 3 \\
\hline Spouse/partner+GP+another doctor & $7188(2.8)$ & 4 & $6110(2.7)$ & 4 \\
\hline Friend & $6270(2.4)$ & 5 & $5463(2.4)$ & 5 \\
\hline Spouse/partner+friend & 4877 (1.9) & 6 & $4524(2.0)$ & 6 \\
\hline Spouse/partner+another doctor & $4479(1.7)$ & 7 & $3876(1.7)$ & 7 \\
\hline GP & $3898(1.5)$ & 8 & $2885(1.3)$ & 10 \\
\hline Spouse/partner+colleague & $3601(1.4)$ & 9 & $3360(1.5)$ & 8 \\
\hline Spouse/partner+children & $3504(1.4)$ & 10 & $3183(1.4)$ & 9 \\
\hline Spouse/partner+parent & $2816(1.1)$ & 11 & $2567(1.1)$ & 11 \\
\hline Parent & $2630(0.7)$ & 12 & $2171(1.0)$ & 12 \\
\hline Colleague & $1931(0.7)$ & 13 & $1679(0.7)$ & 13 \\
\hline Spouse/partner+children+GP+another doctor & $1845(0.7)$ & 14 & $1614(0.7)$ & 15 \\
\hline Children & $1839(0.7)$ & 15 & $1440(0.6)$ & 16 \\
\hline Spouse/partner+colleague+friend & $1775(0.7)$ & 16 & $1675(0.7)$ & 14 \\
\hline Another doctor+GP & $1693(0.7)$ & 17 & $1226(0.5)$ & 21 \\
\hline Another doctor & $1660(0.6)$ & 18 & $1280(0.6)$ & 18 \\
\hline Spouse/partner+parent+friend & $1410(0.5)$ & 19 & $1311(0.6)$ & 17 \\
\hline Spouse/partner+children+GP & $1397(0.5)$ & 20 & $1241(0.5)$ & 20 \\
\hline Spouse/partner+physiotherapist/chiropractor & $1382(0.5)$ & 21 & $1264(0.6)$ & 19 \\
\hline
\end{tabular}

*Respondents reporting available personal relations or accessibility to other people.

†Rank according to the subanalysis with respondents who have reported available personal relations or accessibility to other people.

GP, general practitioner.

recall symptoms and whom they talked to or contacted fairly accurately. ${ }^{1819}$

The term symptom as presented in the discipline of biomedicine is influenced by a desire to predict underlying diseases and risks of negative effects on health. From the biomedical perspective, it is common to distinguish between subjective health complaints (symptoms) and signs with the latter being objectively verifiable (eg, blood in the urine or jaundice), whereas symptoms often refer to subjective complaints. The WONCA Dictionary of General/Family Practice defines a symptom as 'any subjective evidence of a health problem as perceived by the patient ${ }^{\prime 20}$ This definition implies that symptom experiences are not viewed as objective, clinical phenomena, but are seen as the result of the patient's own interpretation process, in which bodily sensations or changes are transformed into signs of ill health. ${ }^{21-23}$ Accordingly, we defined subjectively reported symptom experiences as multidimensional constructions embedded in a complex interplay of biological, psychological and cultural factors and interpreted the symptom experiences reported in the survey as reflections of the individually experienced responses to bodily changes or sensations.
There are certain limitations to using data extracted from a questionnaire-based survey; among others it does not allow insight into what kinds of bodily sensations are included or excluded by respondents as symptoms. ${ }^{23}$ Following this line of reflection, the design and scope of the study was not designed to obtain data on the quality or content of the dialogues between the respondents and their network relation(s). Furthermore, the chronological order of the activation of relations was also not able to collected. We can solely describe whether a relation was activated or not.

More response options to symptom experience could have been presented the respondents. Especially using the social media or the internet might have been a common response pattern to symptom experience among the young respondents. However, we chose the personal and professional network relations for simplicity in an already comprehensive questionnaire.

The results presented in this paper are not static nor generic representations of symptom experience management. As repeatedly illustrated in anthropological literature on illness experiences and the management of the body in everyday life, the articulation and management 


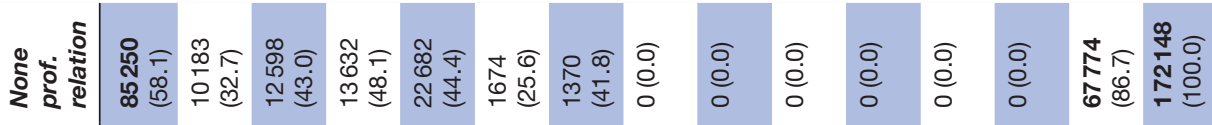

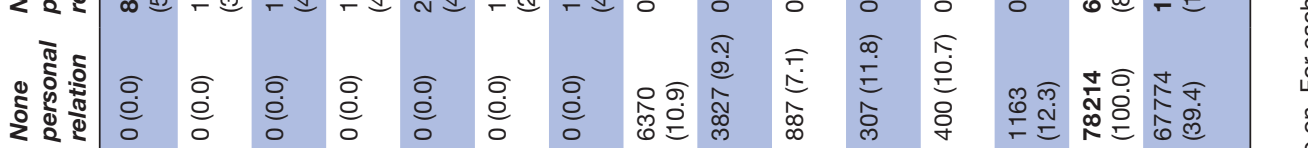

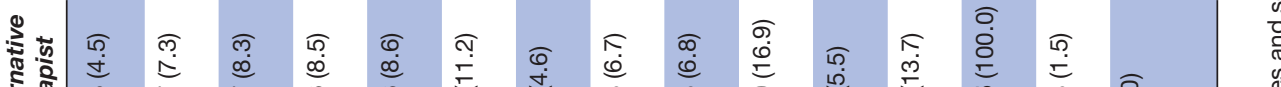

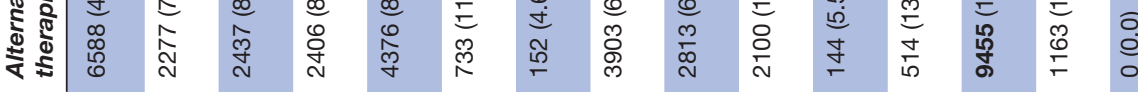

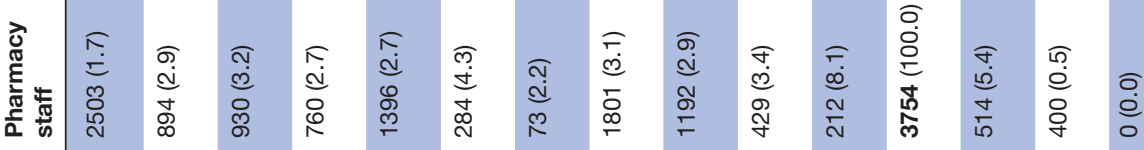

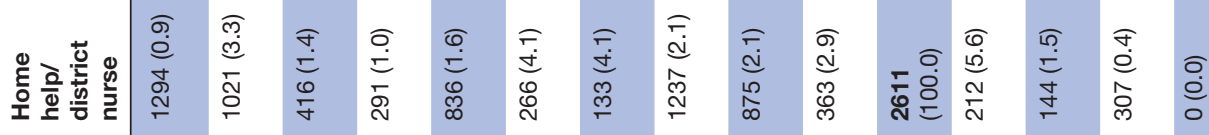

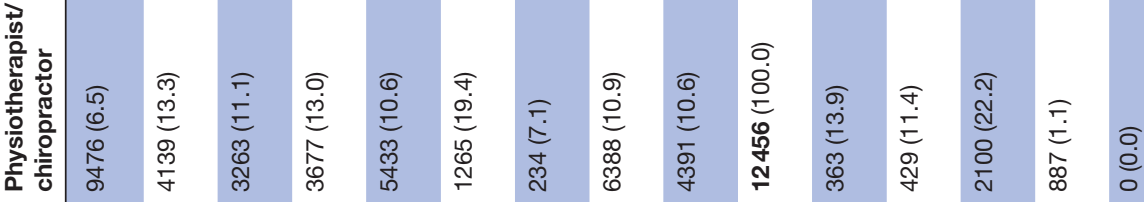

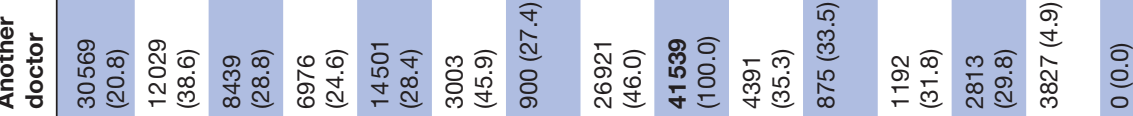

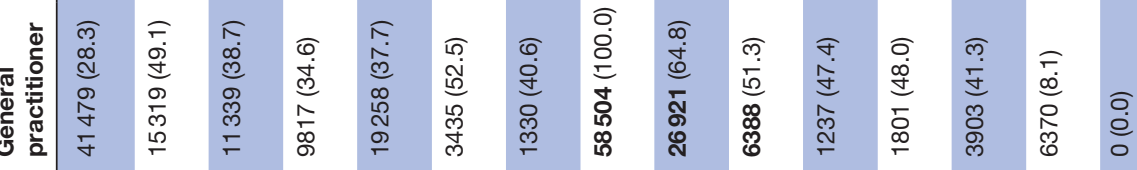

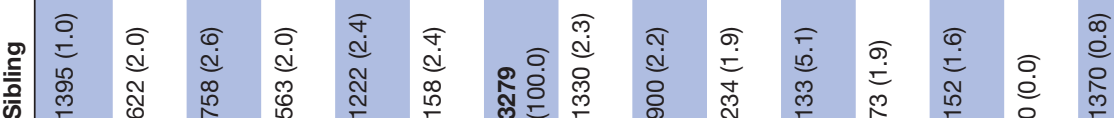

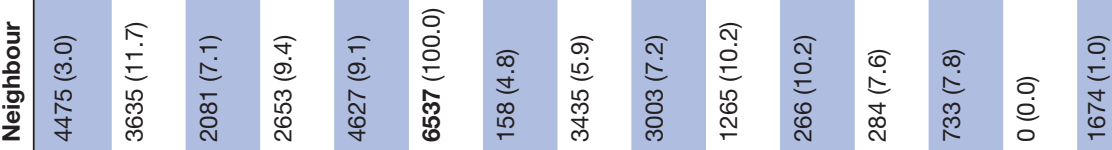

๘

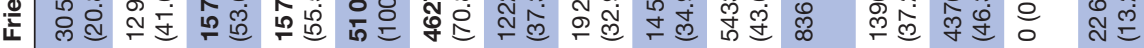

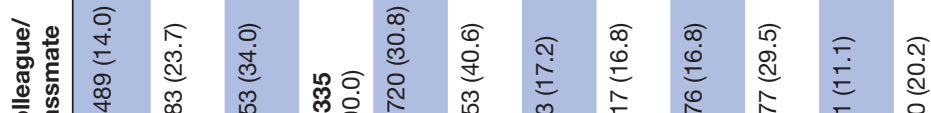

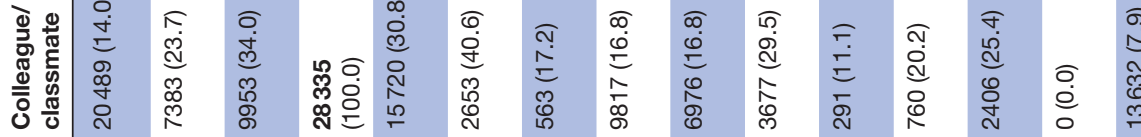

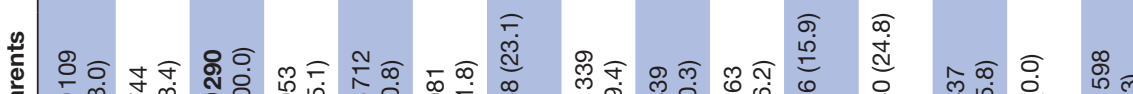

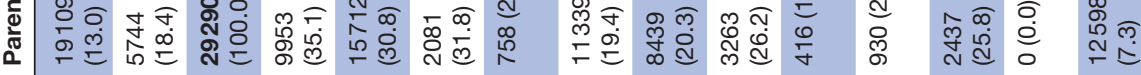

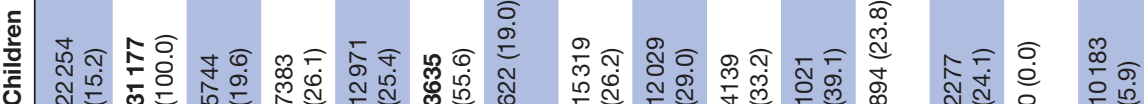

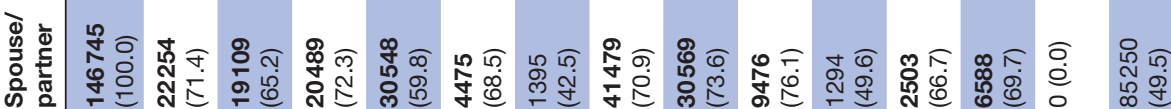


Table 4 The proportion of contacts to professional, personal and 'use of neither personal nor professional' relation with regard to the 44 different symptom experiences

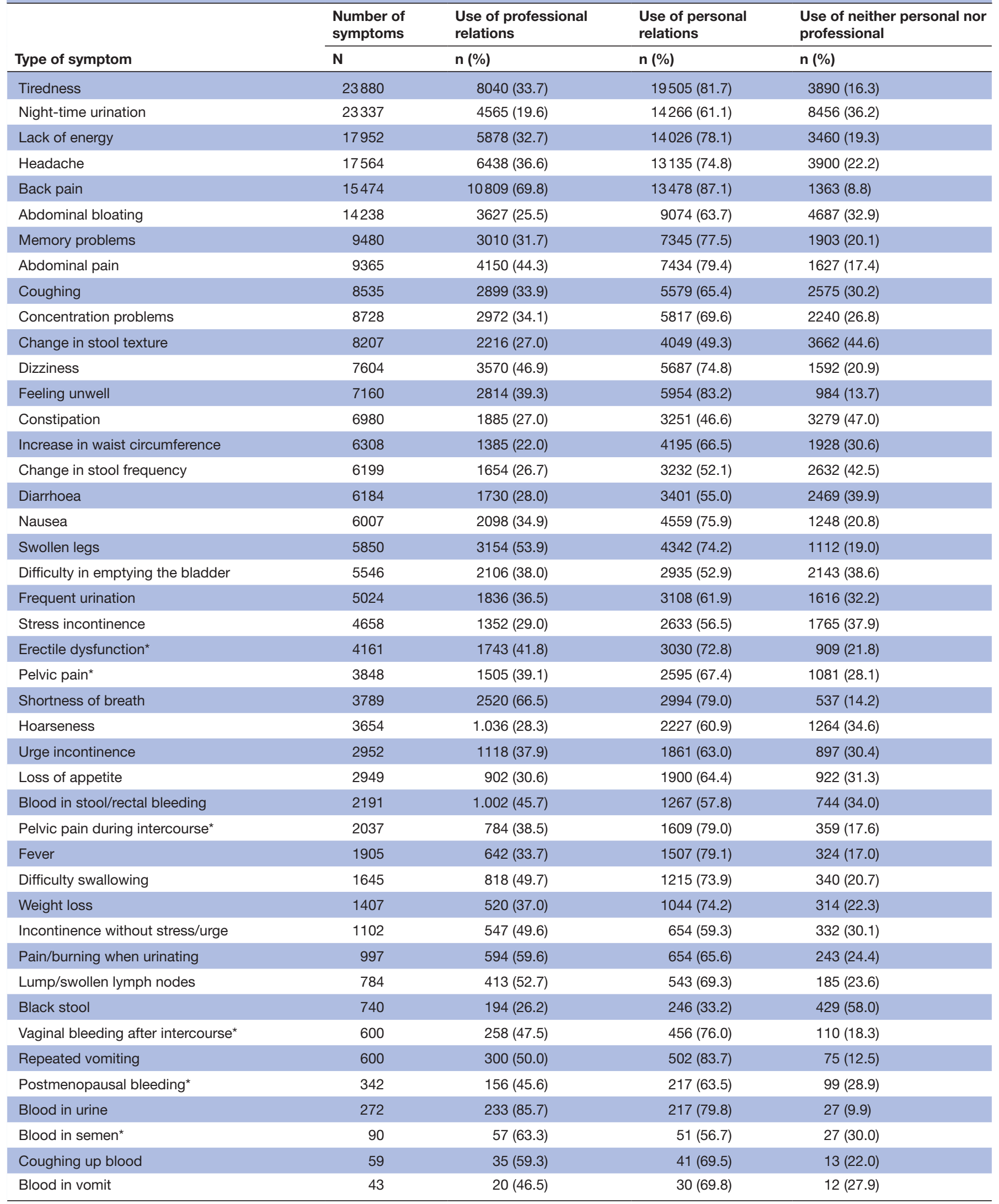

The total number of symptom experiences was 260079 .

${ }^{*}$ Gender-specific symptoms. 
of bodily sensations as symptoms unfold in the relationship between subjective experience and cultural indexations of sensations as symptoms, ${ }^{23}$ as well as existing norms and values that guide population-healthcare system interaction. ${ }^{24}$ What this paper presents is a general 'epidemiology of bodily experience'. How many symptom experiences may be reported in the Danish population at a given moment in time and how do people respond to those experiences. This kind of insight generates knowledge of symptom disclosures which is specific to cultures like Denmark and not necessarily generalisable to other people living in different cultures.

\section{Comparison with existing literature}

In the present study, more than one-fifth of the symptom experiences were shared with the GP. This result is lower compared with Pescosolido, ${ }^{10}$ who found that the GP was involved in $85.4 \%$ of the illness episodes registered in a retrospective survey. The high use of the GP found in Pescosolido ${ }^{10}$ was expected as the study selected episodes of illness on the basis of, for example, severity and recency. In contrast, the findings in the present study were derived from a random sample in an unselected population reporting symptom experiences. Furthermore, the present study was conducted in a gate keeper system with free access to the GP (ie, including through e-mail $)^{25}$ which could theoretically increase the use of the GP compared with the American health system described in Pescosolido. ${ }^{10}$

More than a fourth of the symptom experiences reported did not result in activation of neither a personal nor a professional relation. This finding was lower compared with a recent study performed $(48.6 \%)^{3}$ but generally consistent with studies conducted earlier. ${ }^{26-28}$ Moreover, the overall proportion of GP activation was higher compared with similar studies conducted. ${ }^{326} 27$

Within the present study, the most activated personal relation was the spouse/partner, who was involved in more than half of all the symptoms reported. The fact that the spouse/partner was activated when people experienced a symptom was not surprising, but an interesting aspect in the present study was the fact that only a quarter of all symptoms discussed with the spouse/partner was also presented to the GP, whereas the symptoms discussed with the GP had also been discussed with the spouse/ partner in almost three quarters of the symptom experiences. These findings could indicate that the personal relation can act as a trigger of healthcare seeking. Moreover, the results underline that many symptoms are still kept below the 'water line' of the symptom iceberg.

Various readings of these findings may be presented. It has been suggested that the social management of illness in welfare states is increasingly institutionalised and professionalised. ${ }^{29}$ This would explain why people in our study, to a high degree, seek medical assistance when experiencing symptoms and perhaps also why people seem hesitant in activating personal networks. Overall, it may suggest a form of privatisation of the body, and the results are illustrative of how authority in the social management of illness is increasingly placed in the professional sector.

Nearly 3000 different patterns of activated relations with regard to a symptom experience were revealed in the present study, but the density within the first five patterns accounted for nearly $60 \%$ of all patterns. This was in line with Pescosolido, ${ }^{10}$ who concludes that there appears to be a limited repertoire of patterns of choice, most of them pluralistic and some single.

Furthermore, Pescosolido ${ }^{10}$ only found a few factors influencing which relations were activated when experiencing an illness episode. Those were social characteristics, which differentiated the strategies activated but not whether the GP was contacted. In the present study, people without an available personal network of relations more often activated the GP in comparison to people with a potential social network. Moreover, some of the variation found in the activation of network relations might be explained by a difference in the characteristics of the symptom and the symptom categories. The present study comprises 44 quite diverse symptom categories in contrast to studies only comprised of a few alarming symptoms of cancer. ${ }^{30}$ We found a tendency of solitariness or a higher proportion of not activating a network relation with regard to symptoms originating from the urogenital or colorectal region. This corresponds to findings from the cancer literature, where change in bowel and bladder habits was associated with a longer patient interval ${ }^{8}$ often due to embarrassment, fear or taboo. ${ }^{6}$

\section{Implications for research and practice}

This study adds insights to the research on healthcare seeking and social network by exploring two dimensions of social variation in network activation and use of GP. Reasons for no activation of a network relation when experiencing a symptom can be that people either intentionally chose not to activate anyone in their social network or that people have no access to a social network of relations. In this population-based setting, we found that more than a quarter of all reported symptom experiences were not shared with anyone, neither personal nor professional, regardless of accessibility to social network relations.

The present study speaks in favour of that the social management of illness has been increasingly institutionalised, as people with sparse access to personal network relations made use of the GP to a greater extent, which additionally stresses the GPs role in general but particularly with regard to people lacking available social network relations.

For symptoms related to the urogenital or colorectal region, the activation of either personal or professional relations was relatively low, which might indicate reticence to involve other people when experiencing symptoms connected to these anatomical regions. Further research into the characteristics of potential barriers to contacting the GP about a symptom related to these parts 
of the body would be useful to reduce barriers of communication when contacting a GP.

Contributors SE and DEJ participated in the design of the study, development of the questionnaire, the logistics concerning the survey and the drafting of the manuscript. SE moreover did the main work in forming the manuscript and carried out the statistical analyses. RSA and AFP participated in the design of the study, development of the questionnaire and drafting of the manuscript. Maria Munch Storsveen and René dePont Christensen participated in the statistical considerations concerning the survey and analyses and MMS carried out the statistical analyses. All authors read and approved the final manuscript.

Funding The study is financially supported by the Novo Nordisk Foundation and the Danish Cancer Society. The funding sources had no involvement in the study or in the approval of the manuscript.

Competing interests None declared.

Ethics approval The Regional Scientific Ethics Committee for Southern Denmark evaluated the project and concluded that no further approval was necessary due to Danish legislation. The participants in the study were clearly informed that there would be no clinical follow-up, and that they should contact their own GP in case of concern or worry. The project was approved by the Danish Data Protection Agency (Journal no. 2011-41-6651)

Provenance and peer review Not commissioned; externally peer reviewed.

Data sharing statement The datasets generated and analysed during the current study are not publicly available due to the data protection regulations of the Danish Data Protection, Statistics Denmark and the Danish Health and Medicines Authority. Access to data is strictly limited to the researchers who have obtained permission for data processing. This permission was given to the Research Unit of General Practice, Department of Public Health, University of Southern Denmark.

Open Access This is an Open Access article distributed in accordance with the Creative Commons Attribution Non Commercial (CC BY-NC 4.0) license, which permits others to distribute, remix, adapt, build upon this work non-commercially, and license their derivative works on different terms, provided the original work is properly cited and the use is non-commercial. See: http://creativecommons.org/ licenses/by-nc/4.0/

(C) Article author(s) (or their employer(s) unless otherwise stated in the text of the article) 2017. All rights reserved. No commercial use is permitted unless otherwise expressly granted.

\section{REFERENCES}

1. Last JM. The Iceberg "Completing the clinical picture" in general practice. The Lancet 1963;282:28-31.

2. Hannay DR, Maddox EJ. Incongruous referrals. Lancet 1975;2:1195-7

3. Elliott AM, McAteer A, Hannaford PC. Revisiting the symptom iceberg in today's primary care: results from a UK population survey. BMC Fam Pract 2011;12:16.

4. Whitaker KL, Macleod U, Winstanley K, et al. Help seeking for cancer 'alarm' symptoms: a qualitative interview study of primary care patients in the UK. Br J Gen Pract 2015;65:e96-e105.

5. McCutchan GM, Wood F, Edwards A, et al. Influences of cancer symptom knowledge, beliefs and barriers on cancer symptom presentation in relation to socioeconomic deprivation: a systematic review. BMC Cancer 2015;15:1000.

6. Smith LK, Pope C, Botha JL. Patients' help-seeking experiences and delay in cancer presentation: a qualitative synthesis. Lancet 2005;366:825-31.
7. Walter F, Webster A, Scott S, et al. The Andersen model of total patient delay: a systematic review of its application in cancer diagnosis. $J$ Health Serv Res Policy 2012;17:110-8.

8. Macleod U, Mitchell ED, Burgess C, et al. Risk factors for delayed presentation and referral of symptomatic cancer: evidence for common cancers. Br J Cancer 2009;101 Suppl 2:S92-S101.

9. Pedersen AF, Olesen F, Hansen RP, et al. Social support, gender and patient delay. Br J Cancer 2011;104:1249-55.

10. Pescosolido BA. Beyond rational choice: the social dynamics of how people seek help. Am J Sociol 1992;97:1096-138.

11. Rasmussen S, Søndergaard J, Larsen PV, et al. The Danish symptom cohort: questionnaire and feasibility in the nationwide study on symptom experience and healthcare-seeking among 100000 ilndividuals. Int J Family Med 2014;2014:1-10.

12. Elnegaard S, Andersen RS, Pedersen AF, et al. Self-reported symptoms and healthcare seeking in the general populationexploring "The Symptom Iceberg". BMC Public Health 2015;15:685.

13. Pedersen CB, Gøtzsche H, Møller JO, et al. The Danish Civil Registration System. A cohort of eight million persons. Dan Med Bull 2006;53:441-9.

14. Whitaker KL, Scott SE, Winstanley K, et al. Attributions of cancer 'alarm' symptoms in a community sample. PLoS One 2014:9:e114028.

15. Rothman KJ. Epidemiology: an introduction. Oxford University Press, 2012.

16. McColl E. Best practice in symptom assessment: a review. Gut 2004;53(Suppl 4):iv49-54.

17. Jenkins $P$, Earle-Richardson G, Slingerland DT, et al. Time dependent memory decay. Am J Ind Med 2002;41:98-101.

18. Steen N, Hutchinson A, McColl E, et al. Development of a symptom based outcome measure for asthma. BMJ 1994;309:1065-8.

19. Stull DE, Leidy NK, Parasuraman B, et al. Optimal recall periods for patient-reported outcomes: challenges and potential solutions. Curr Med Res Opin 2009;25:929-42.

20. Bentzen N, Bridges-Webb C. An international glossary for general/ family practice. Fam Pract 1995;12:267.

21. Andersen RS, Paarup B, Vedsted P, et al. 'Containment' as an analytical framework for understanding patient delay: a qualitative study of cancer patients' symptom interpretation processes. Soc Sci Med 2010;71:378-85.

22. Petrie KJ, Weinman J. Why illness perceptions matter. Clin Med 2006;6:536-9.

23. Rikke Sand A, Mark N, Mette Bech R. Sensations, Symptoms and Healthcare Seeking. 2017;24:1-5.

24. Peter V, Rikke Sand A. Sara Marie Hebsgaard O. 'The Good Citizen': balancing moral possibilities in everyday life between sensation, symptom and healthcare seeking. 2017;24:6-12.

25. Pedersen KM, Andersen JS, Søndergaard J. General practice and primary health care in Denmark. J Am Board Fam Med 2012;25 Suppl 1:S34-S38.

26. Verbrugge LM, Ascione FJ. Exploring the iceberg. Common symptoms and how people care for them. Med Care 1987:25:539-69.

27. White KL, Williams TF, Greenberg BG. The ecology of medical care. N Engl J Med 1961;265:885-92.

28. Stoller EP, Forster LE, Portugal S. Self-care responses to symptoms by older people. A health diary study of illness behavior. Med Care 1993;31:24-42.

29. Petersen A, Lupton D. The new public health: Health and self in the age of risk. Sage Publications, Inc, 1996.

30. Burgess C, Hunter MS, Ramirez AJ. A qualitative study of delay among women reporting symptoms of breast cancer. $\mathrm{Br} J$ Gen Pract 2001:51:967-71.

31. Svendsen RP, Jarbol DE, Larsen PV, et al. Associations between health care seeking and socioeconomic and demographic determinants among people reporting alarm symptoms of cancer: a population-based cross-sectional study. Fam Pract 2013;30:655-65. 